\title{
Investigation of Kelvin Waves in the Stratosphere Using FORMOSAT-3/COSMIC Temperature Data
}

\author{
C. J. PAN, Uma DAS, S. S. YANG \\ Institute of Space Sciences, National Central University, Jhongli, Taiwan \\ C. J. WONG \\ School of Physics, Universiti Sains Malaysia, Malaysia \\ and \\ H. C. LAI \\ Department of Engineering \& Management of Advanced Technology, Chang Jung University, Taiwan \\ (Manuscript received 31 May 2010, in final form 16 September 2010)
}

\begin{abstract}
Temperature data from Global Positioning System based Radio Occultation (GPS RO) soundings of the Formosa Satellite mission 3/Constellation Observing System for Meteorology, Ionosphere, and Climate (FORMOSAT-3/COSMIC or F-3/C) micro satellites has been investigated in detail to study the Kelvin wave properties. The high temporal and spatial resolution satellite data from August 2006 to August 2009 have enabled the investigation of Kelvin wave activity on each day. The dominant waves of wave numbers 1 and 2 (W1 and W2) have been investigated in detail at three altitudes-19, 25 and $30 \mathrm{~km}$, and it is found that the amplitude of $\mathrm{W} 1$ is greater than that of W2 during $60 \%$ of the time. A statistical study of the amplitudes of W1 and W2 is also presented and it is found that the dominant amplitudes are 0.5 to $1.0 \mathrm{~K}$ for both waves. At lower altitudes $(19 \mathrm{~km})$, the amplitudes of W1 are larger and the distribution is also broader. The amplitudes of both waves in the stratosphere are higher during the easterlies of the quasi-biennial oscillation (QBO) and are maximum when the zonal wind changes from easterlies to westerlies. In the lower altitudes near the tropopause they vary in consonance with the outgoing long wave radiation, a proxy of deep convection. Deduction of the Kelvin wave periods and phase velocities has been possible with better accuracy with the use of the F-3/C data. The average periods of $\mathrm{W} 1$ for all years are $15 \pm 3,13 \pm 4$, and $10 \pm 3$ days at altitudes 19,25 , and $30 \mathrm{~km}$, respectively and the average periods of $\mathrm{W} 2$ for all years are $10 \pm 2,7 \pm 2$, and $6 \pm 2$ days, respectively. These standard deviations are geophysical and are due to the variation in the periods of the individual Kelvin wave events and identification of the period for a single Kelvin wave event is correct to within \pm one day. We found that the Kelvin waves of both the zonal wave numbers are slow in the lower altitudes and fast in the higher altitudes. Also, the periods decrease gradually with height. This is the most important result of the present study.
\end{abstract}

Corresponding author: C. J. Pan, Institute of Space Sciences, National Central University, Jhongli 32001 Taiwan.

E-mail: cjpan@jupiter.ss.ncu.edu.tw

(C) 2011, Meteorological Society of Japan

\section{Introduction}

Kelvin waves play a very important role in the dynamics of the upper troposphere and lower stratosphere (UTLS). They carry westerly momentum upwards and are damped by radiative cooling, small scale turbulence, and critical level interac- 
tions. As the waves are damped they lose momentum and accelerate the westerly mean flow of the quasi-biennial oscillation (QBO). The vertical component of the group velocity decreases with time and the Kelvin waves are damped at lower heights causing the westerly zone to descend (Holton and Lindzen 1972). Recent studies show that in addition to the planetary scale waves, inertia gravity waves carrying a higher momentum flux are also responsible for driving the QBO (Baldwin et al. 2001 and references therein). However, the quantification of the contributions of each of these waves to the dynamics of UTLS is still unclear. Also, Kelvin waves are known to affect the dynamics, cloud physics and transport around the tropical tropopause layer (TTL; Fueglistaler et al. 2009 and references therein), and ultrafast Kelvin waves can propagate upward to thermospheric heights altering the neutral and electron densities at those heights (e.g., Chang et al. 2010). It is, therefore, absolutely necessary to understand in itself the long term properties and propagation characteristics of the Kelvin waves in the stratosphere.

Kelvin waves in the atmosphere were first suggested by Matsuno (1966) and Holton and Lindzen (1968) discussed them specifically - a special solution to linearized equations for an equatorial $\beta$ plane. Later, Wallace and Kousky (1968) showed observational evidences in the tropical stratospheric zonal winds and temperature using radiosonde data. The phase propagation was eastward and downward and the wave motion was in the zonal and vertical directions only. There was no meridional component observed. The average period of the waves was 15 days and the amplitude was $8-$ $12 \mathrm{~m} / \mathrm{s}$ in the zonal wind and $3-5^{\circ} \mathrm{C}$ in temperature. Also, the temperature was found to lead the zonal wind by $1 / 4$ cycle. Many studies followed using data from radiosondes which were confined to a particular location (Shiotani and Horinouchi 1993, etc.).

When the satellite era began, it gave an opportunity to investigate the global structure of these waves. Temperature data from Limb Infrared Monitor of the Stratosphere (LIMS) on board Nimbus-7 (Salby et al. 1984), Microwave Limb Sounder (MLS) onboard the Upper Atmosphere Research Satellite (UARS; Canziani et al. 1994, Mote et al. 2002), and from Cryogenic Limb Array Etalon Spectrophotometer (CLAES) onboard UARS (Shiotani et al. 1997) were used to investigate Kelvin waves and their properties. Slow, fast and ultrafast Kelvin waves of zonal wave numbers
1 and 2 with periods varying from 4-15 days were identified. The amplitude of the waves was maximum over the equator. The most intense investigations began when data from the Radio Occultations (RO) of the Global Positioning System (GPS) were available. A low earth orbiting satellite measures the occulted GPS satellite signals as it sets below the Earth's horizon relative to any of the GPS Satellites. The first of its kind dataset was that of GPS/ MET (Global Positioning System METeorology) during the period from April 1995 to February 1997. Tsuda et al. (2000) showed that this temperature data obtained from the GPS/MET observations can be used for the study of gravity wave activity in the stratosphere. Randel et al. (2003) also used the GPS/MET dataset to investigate the cold point tropopause features and found that the tropopause variations are related to gravity waves and/or Kelvin waves.

The next set of GPS RO data was from the satellites CHAMP and SAC-C, which provided temperature profiles that were used to investigate the properties of Kelvin waves in greater detail (Tsai et al. 2004; Randel and Wu 2005; Tsuda et al. 2006; Ratnam et al. 2006). Tsai et al. (2004) developed a very unique method to analyze the GPS RO data for studies of Kelvin waves with zonal wave numbers 1 and 2 using the CHAMP and SAC-C data during 2001-2002. The amplitude of temperature fluctuations was found to be $2 \mathrm{~K}$ in general with wave periods of 12.5-14 days for zonal wave number 1 and 9.3-11.0 days for wave number 2 at $19 \mathrm{~km}$ altitude. Randel and $\mathrm{Wu}$ (2005) extended this work and found that the amplitudes are maximum near the tropopause and in the stratosphere enhanced amplitudes coincide with the descending westerly shear phase of the QBO. It was also seen that the global temperature patterns over $12-17 \mathrm{~km}$ vary coherently with transient deep convection over Indonesia. Tsuda et al. (2006) investigated the Kelvin waves during the CPEA campaign consisting of intensive balloon soundings for a month from 10 April to 9 May, 2004 and additionally using CHAMP data. They made a very good comparative study between the two datasets and found the following. The fluctuations observed by GPS RO generally agreed well with the radiosonde data above $18 \mathrm{~km}$. However near and below the tropopause the agreement was not good suggesting the fact that the horizontal scales involved at these altitudes are smaller than the wave numbers 1 and 2. Long term behavior 
of the Kelvin wave activity was discussed by Ratnam et al. (2006) using the long term dataset of CHAMP from 2001 to 2005. All other earlier studies were limited to periods of one year and less. Though all these studies have investigated the Kelvin waves in detail, the temporal and the spatial resolutions of the data sets that were used were coarse. Also, most of these studies concentrated on the wave properties in the lower altitudes near the tropopause $(17-20 \mathrm{~km})$.

With the launch of FORMOSAT-3/COSMIC (Formosa Satellite \#3 and Constellation Observation System for Meteorology, Ionosphere and Climate: F-3/C) the number of soundings of the atmosphere has increased tremendously resulting in very high spatial and temporal resolutions of the atmospheric measurements. F-3/C is a collaborative project of the National Space Organization (NSPO) in Taiwan and the University Corporation of Atmospheric Research (UCAR), USA. The F-3/C constellation consists of six micro-satellites equipped with advanced GPS receivers for radio occultation measurements. The next section describes the F-3/C mission, the dataset and the procedure of data analysis used in the present study to investigate Kelvin waves. Section 3 describes and discusses the results in detail and compares and contrasts them with earlier findings. This study will show that the high quality of F-3/C data has an edge over all previous datasets with its high spatial and temporal resolutions and the investigations of the Kelvin waves are thus carried out with greater detail.

\section{Data and analysis}

The six F-3/C micro satellites were launched into a circular, $72^{\circ}$ inclination orbit at an altitude of $512 \mathrm{~km}$ on 15 April 2006. The mission goal was to deploy the six satellites into six orbit planes at $800 \mathrm{~km}$ with a 30 degree separation for evenly distributed global coverage which is now currently achieved. It is the first constellation of satellites for monitoring global weather and ionospheric electron density distribution using the GPS RO technique. For the lower atmosphere, COSMIC provides the refractivity profiles, which are processed real-time by the COSMIC Data Analysis and Archive Center (CDAAC) at the University Corporation for Atmospheric Research (UCAR) to give profiles of temperature and water vapor. Further details regarding the spacecraft constellation system can be obtained from Fong et al. (2009). A long database of temperature in the UTLS region from August 2006 to August 2009 is analyzed in the present study to investigate in detail the structure and properties of equatorial atmospheric Kelvin waves. Figure 1a shows a histogram of the number of profiles that were available from all the six COSMIC satellites in each month with an average of almost 47000 profiles per month, with a nearly uniform distribution around the globe. The Kelvin waves have maximum amplitude over the equator and so the

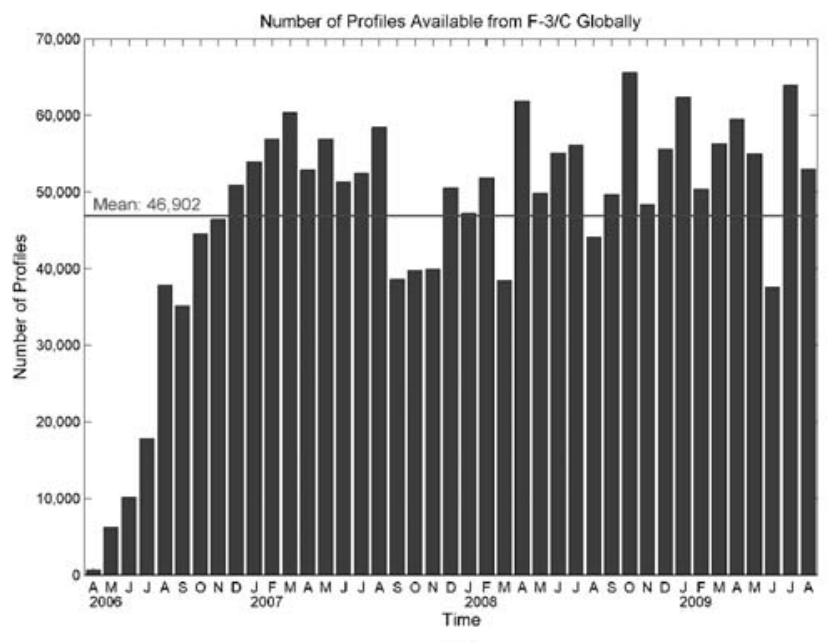

(a)

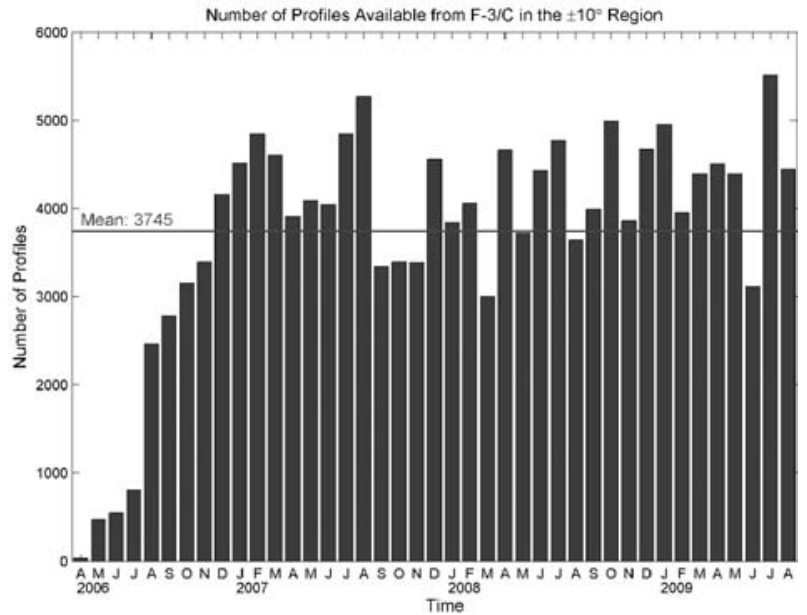

(b)

Fig. 1. Monthly number of profiles available from the FORMOSAT-3/COSMIC observations (a) on a global scale and $(\mathrm{b})$ in the $\pm 10^{\circ}$ latitude region. 
Temperature Fluctuations - December 10, 2007

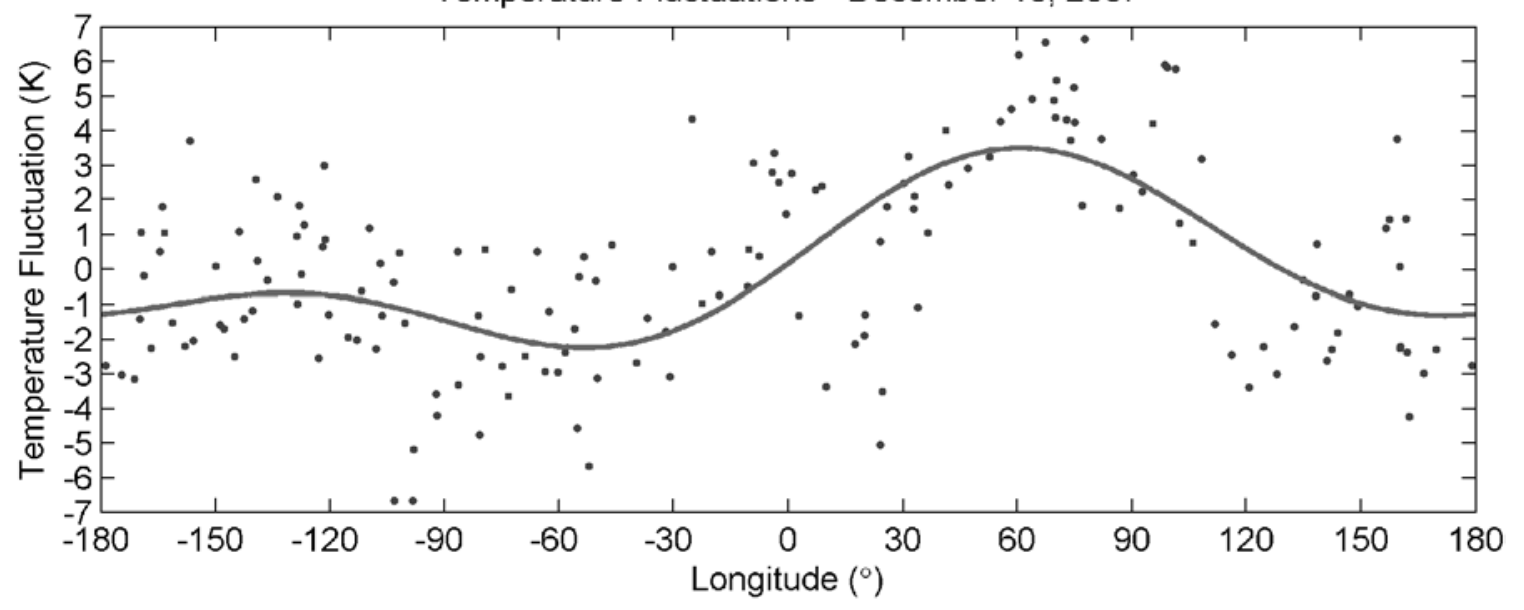

Fig. 2. Temperature fluctuations at $19 \mathrm{~km}$ altitude on 10 December 2007. The number of measurements available on this day is 163 and they are shown by the blue dots. The red solid line is the best fit for zonal wave numbers 1 and 2.

investigations are confined to the equatorial belt from $10^{\circ} \mathrm{N}-10^{\circ} \mathrm{S}$ (Mote et al. 2002). An added advantage of this is that the contamination by waves from other latitudinal regions is also minimized. Figure $1 \mathrm{~b}$ shows the number of profiles available in the region of interest, i.e., in the $\pm 10^{\circ}$ region and the average number of profiles per month is almost 4,000 . This shows that the average number of profiles per day is greater than 125 (except for a few initial months of the COSMIC observations). This data availability is more than a magnitude higher than the amount of data available from CHAMP and SAC-C, which is only $10-13$ profiles per day (Tsai et al. 2004).

The data used in the present study comprises of COSMIC version 2.0 'wet' temperature profiles from 10 to $40 \mathrm{~km}$ altitude. Water vapor information is included in retrieving the 'wet' temperature from COSMIC observations, and it shows significant differences from the 'dry' temperature only at altitudes below $10 \mathrm{~km}$. In the present altitude region of interest, both wet and dry temperature profiles are similar. There have been a few studies on the validation of the COSMIC temperature data. Rao et al. (2009) performed a validation study of this data over Gadanki $\left(13.48^{\circ} \mathrm{N}, 79.2^{\circ} \mathrm{E}\right)$, a tropical region. A very good comparison was found with the radiosonde temperature observations with a mean difference of less than $1 \mathrm{~K}$ from 10 to $27 \mathrm{~km}$. Between 30 and $40 \mathrm{~km}$, a large difference of $8 \mathrm{~K}$ was found when compared with lidar observations. Hayashi et al. (2009) also showed good comparisons between COSMIC RO and the radiosonde refractivity profiles with $1-2 \%$ mean difference. Kishore et al. (2009) performed a validation study using the operational stratospheric analyses including the National Centers for Environmental Prediction-Reanalysis (NCEP), the Japanese 25year Reanalysis (JRA-25), and the United Kingdom Met Office (UKMO) data sets. Good agreement was observed between the COSMIC and the various reanalysis outputs, with mean global differences and differences in the height range from 8 to $30 \mathrm{~km}$ being less than $1 \mathrm{~K}$. Largest deviations were observed spatially over polar latitudes and altitudewise at the tropical tropopause with differences being $2-4 \mathrm{~K}$. In the present study, we are investigating the COSMIC temperatures over the equatorial region above the tropopause layer and hence the above validation studies show that in this region of interest COSMIC data is of good quality.

The analysis of the COSMIC data is done as per the procedure described by Tsai et al. (2004) and is briefly described below. For the CHAMP data, data from 3 days was combined and shifted to the middle date to investigate the Kelvin wave properties. Using this method, waves with periods greater than 10 days and those with reduced amplitudes for less than 7 days were studied. As three days of data were taken together, i.e., \pm 1 days of data have been considered on a day, the properties of the waves that have been determined from the analysis are correct to \pm 2 days. The same method is followed in the present study. However, data on each day is 
(a) $19 \mathrm{~km}$

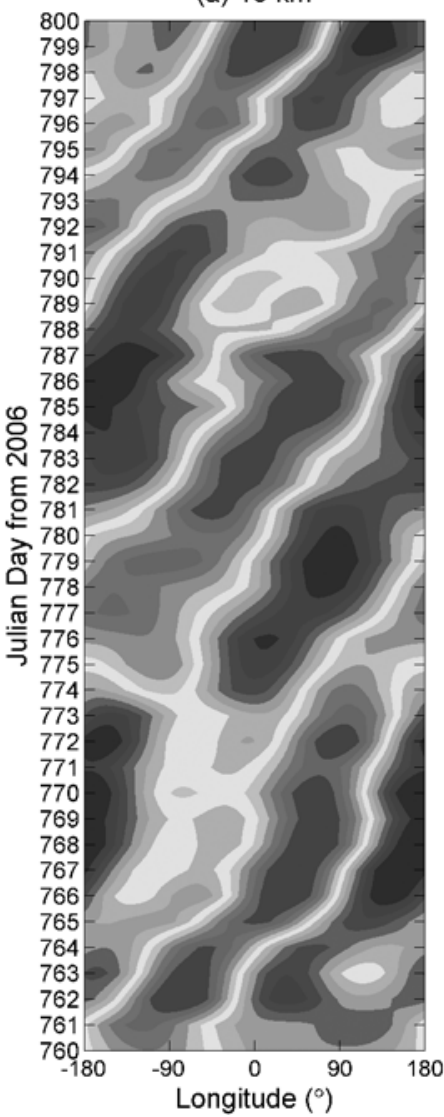

(b) $25 \mathrm{~km}$

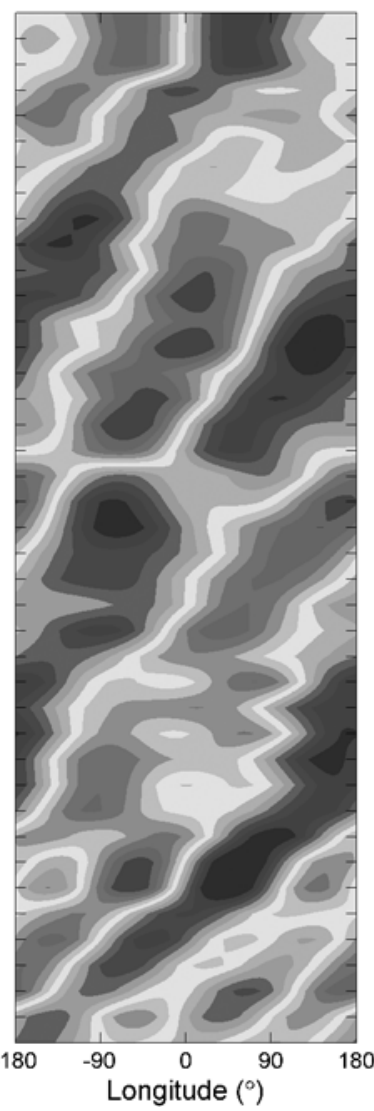

(c) $30 \mathrm{~km}$

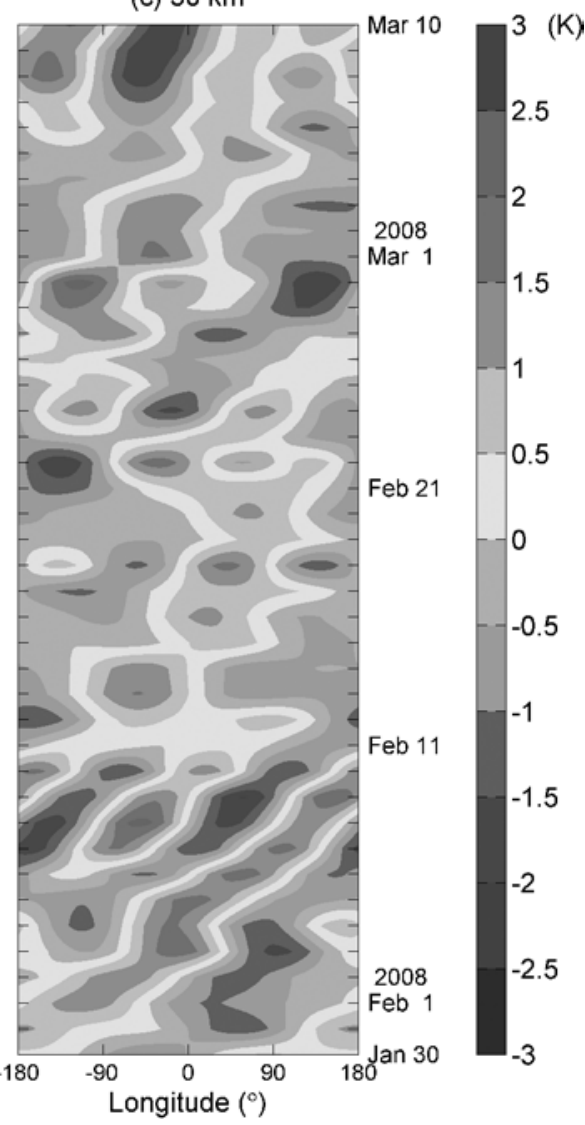

Fig. 3. Hovmoller diagrams of the fitted temperature fluctuations during the period from February to March 2008, at 19, 25 and $30 \mathrm{~km}$ altitudes to show the Kelvin wave features.

analyzed separately so that the errors are limited to \pm 1 day. Each temperature profile is interpolated with $0.1 \mathrm{~km}$ spacing from 10 to $40 \mathrm{~km}$ and 31-day (15 before and 15 later) median profiles are subtracted to obtain the temperature fluctuations $\left(\mathrm{T}^{\prime}\right)$. Figure 2 shows an example of these temperature fluctuations on a typical day, 10 December 2007, at $19 \mathrm{~km}$ altitude as a function of longitude. Although there are many modes present, especially near the tropopause, it is known that the dominant zonal wave numbers of the equatorial Kelvin waves in the middle stratosphere are 1 and 2 (Salby et al. 1984, Mote et al. 2002) and the same can also be seen from Fig. 2. To isolate these waves, a function $f(x)$ of the form,

$$
f(x)=\sum_{s=1}^{2} A_{s} \sin \left(\frac{2 \pi}{360 / s} x-\phi_{s}\right)
$$

is fitted to the temperature fluctuations at each altitude by the least squares method. $A$ and $\phi$ are the amplitude and phase of the waves and $s$ is the zonal wave number. Wave structures corresponding to $s=1$ and $s=2$ are hereafter called $\mathrm{W} 1$ and $\mathrm{W} 2$. The function, $f(x)$, is called the "fitted T's" and is shown as the solid red line in Fig. 2. The fitted zonal waves $\mathrm{W} 1$ and $\mathrm{W} 2$ are then investigated separately and in detail to characterize the equatorial Kelvin waves.

\section{Results and discussion}

Figure 3 shows the time longitude sections, i.e., the Hovmoller diagrams, of the fitted T's during the period from February to March 2008 at 19, 25, and $30 \mathrm{~km}$, as examples for the Kelvin wave events at different altitudes. We chose these specific altitudes for the following reasons. Investigation of the Kelvin waves at $19 \mathrm{~km}$ is important to compare and contrast the wave properties obtained from the F-3/C observations with those of the earlier studies, 
which have mostly concentrated on this altitude near the tropopause. In addition, to investigate the similarities and differences in the horizontal propagation properties of these waves at other altitudes, we chose 25 and $30 \mathrm{~km}$ also. Eastward propagating structures that are seen at all the three altitudes in Fig. 3 are identified as the equatorial Kelvin waves. The periods of these waves are 15, 13, and 10 days at the three altitudes, respectively. It can be noted here that the eastward propagation is not very strict at $30 \mathrm{~km}$, the amplitude is less and it is quasi-stationary sometimes.

The amplitudes, $A_{1}$ and $A_{2}$, of the waves W1 (black) and W2 (blue), respectively, on each day are shown in Fig. 4 for the three altitudes (four panels for each altitude and each panel for a year from 2006 to 2009). There is no specific correlation observed between the two waves. It is found that the amplitude of $\mathrm{W} 1$ is greater than that of $\mathrm{W} 2$ during $60 \%$ of the time during the three year period investigated and the amplitude of $\mathrm{W} 2$ is greater than that of $\mathrm{W} 1$ during $40 \%$ of the time. A statistical study of the amplitudes of the waves W1 and W2 has been conducted, to find the dominant amplitudes at each altitude and also to investigate year to year variations. Figure 5 shows histograms of percentage occurrence of the amplitudes of W1 (left column) and W2 (right column) at $19 \mathrm{~km}$ (bottom row), $25 \mathrm{~km}$ (middle row), and $30 \mathrm{~km}$ (top row) during different years from 2006 to 2009. It can be seen that the distribution is broader at $19 \mathrm{~km}$ for $\mathrm{W} 1$ and amplitudes from $0.5-1.5 \mathrm{~K}$ are dominating, with a percentage occurrence of $25-$ $35 \%$. On the other hand, the amplitude of W2 at $19 \mathrm{~km}$ shows a narrower distribution with the 0.5-1.0 K amplitudes dominating and a percentage occurrence of $35-45 \%$. At 25 and at $30 \mathrm{~km}$, the dominant amplitude for both waves is $0.5-1.0 \mathrm{~K}$, with $40-50 \%$ occurrence. W1 with larger amplitudes of $2.0-2.5 \mathrm{~K}$ also occur for $5-10 \%$ of the time at $19 \mathrm{~km}$. At other altitudes, this percentage occurrence is below $5 \%$. For wave W2, the percentage occurrence of higher amplitudes is below $4 \%$ at $19 \mathrm{~km}$ and negligible at other altitudes. This shows that the occurrence of amplitudes greater than $0.5 \mathrm{~K}$ is always less for $\mathrm{W} 2$ in comparison to that of W1. W2 dominates the occurrence of the smaller amplitudes $(<0.5 \mathrm{~K})$ at all altitudes. Tsai et al. (2004) had reported using CHAMP data that the W1 and W2 components of the Kelvin waves existed in a mixed state and the individual waves were dominant only during small periods. In the present study also, the amplitudes of the waves $\mathrm{W} 1$ and W2 show that they exist simultaneously with small differences in the distribution patterns (Figs. 4, 5). W1 has large amplitudes especially at low altitudes and at higher altitudes the amplitudes of $\mathrm{W} 1$ and W2 show similar variations. The dominant amplitudes for both waves were $0.5-1 \mathrm{~K}$ and so the total amplitude of the mixed Kelvin waves (when in phase) in general is $1-2 \mathrm{~K}$. Tsai et al. (2004) also reported $2 \mathrm{~K}$ to be the amplitude of the Kelvin waves in general. The long term study of these waves performed by Ratnam et al. (2006) using the CHAMP data from 2001 to 2005 also showed similar results.

The figure also shows that, there exists a year to year variation in the distribution of the amplitudes, though the differences are small. The occurrence of larger amplitudes $(>1 \mathrm{~K})$ for both waves is high during 2006 \& 2007 at $30 \mathrm{~km}$, during 2007 at $25 \mathrm{~km}$, and during 2007 \& 2009 at $19 \mathrm{~km}$. Simultaneously, the occurrence of the smaller amplitudes $(<1 \mathrm{~K})$ during these periods and altitudes is low in comparison to the other years. This variation is understood when one investigates these amplitudes in comparison with the background zonal winds. Figure 6 shows the monthly mean amplitudes of W1 and W2 during the study period at all altitudes from 10 to $40 \mathrm{~km}$. Over plotted are the contours of zero-wind, strong easterlies $\left(30 \mathrm{~m} \mathrm{~s}^{-1}\right)$ and strong westerlies $\left(15 \mathrm{~m} \mathrm{~s}^{-1}\right)$ from the monthly mean zonal wind over Singapore $\left(1.37^{\circ} \mathrm{N}, 103.8^{\circ} \mathrm{E}\right)$ obtained from the UKMO standard radiosonde data. These contours are plotted to understand the Kelvin wave amplitudes in relation to the zonal winds in the UTLS region. It can be seen from this figure that the wave amplitudes are indeed high during the aforementioned periods at stratospheric altitudes (during 2006 \& 2007 at $30 \mathrm{~km}$ and during 2007 at $25 \mathrm{~km}$ ) and they bear a strong relation to the QBO. The amplitudes of both Kelvin waves, $\mathrm{W} 1$ and $\mathrm{W} 2$, in the stratosphere are high during the easterlies and maximum at the altitudes when the zonal wind changes direction from easterlies to westerlies. For example, during a period of the easterlies (April to July 2007), the eastward Kelvin waves propagate upward and at a critical level (30$35 \mathrm{~km}$ ) they are damped and deposit their westerly momentum. This provides the required momentum for the zonal wind and the easterlies change to the westerlies. As the direction of the wind changes, the Kelvin waves during the later period (July to October 2007) cannot travel to higher altitudes and are 

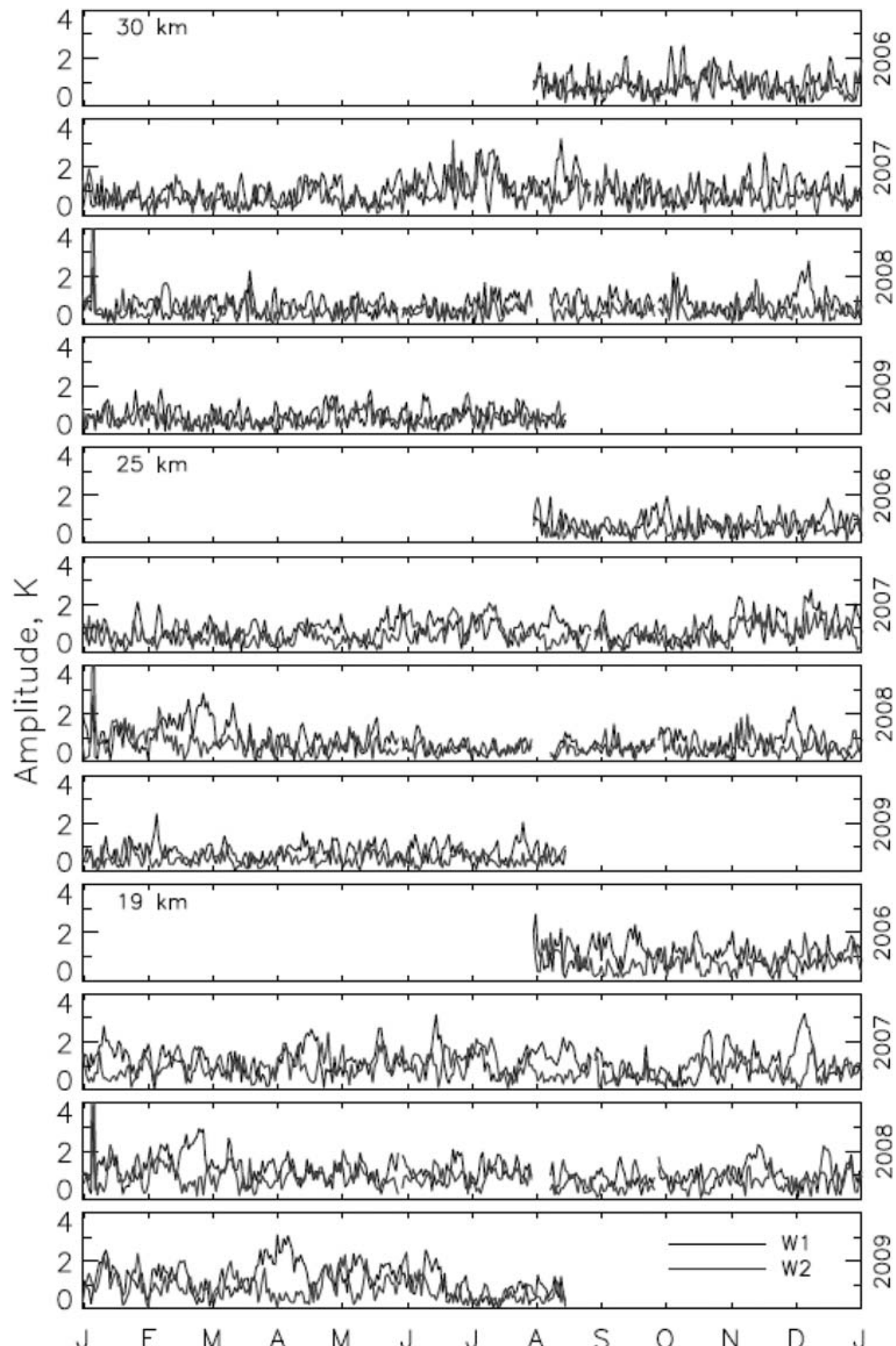

Fig. 4. The amplitudes of W1 and W2 at 19, 25 and $30 \mathrm{~km}$ altitudes, during the period from August 2006 to August 2009. 


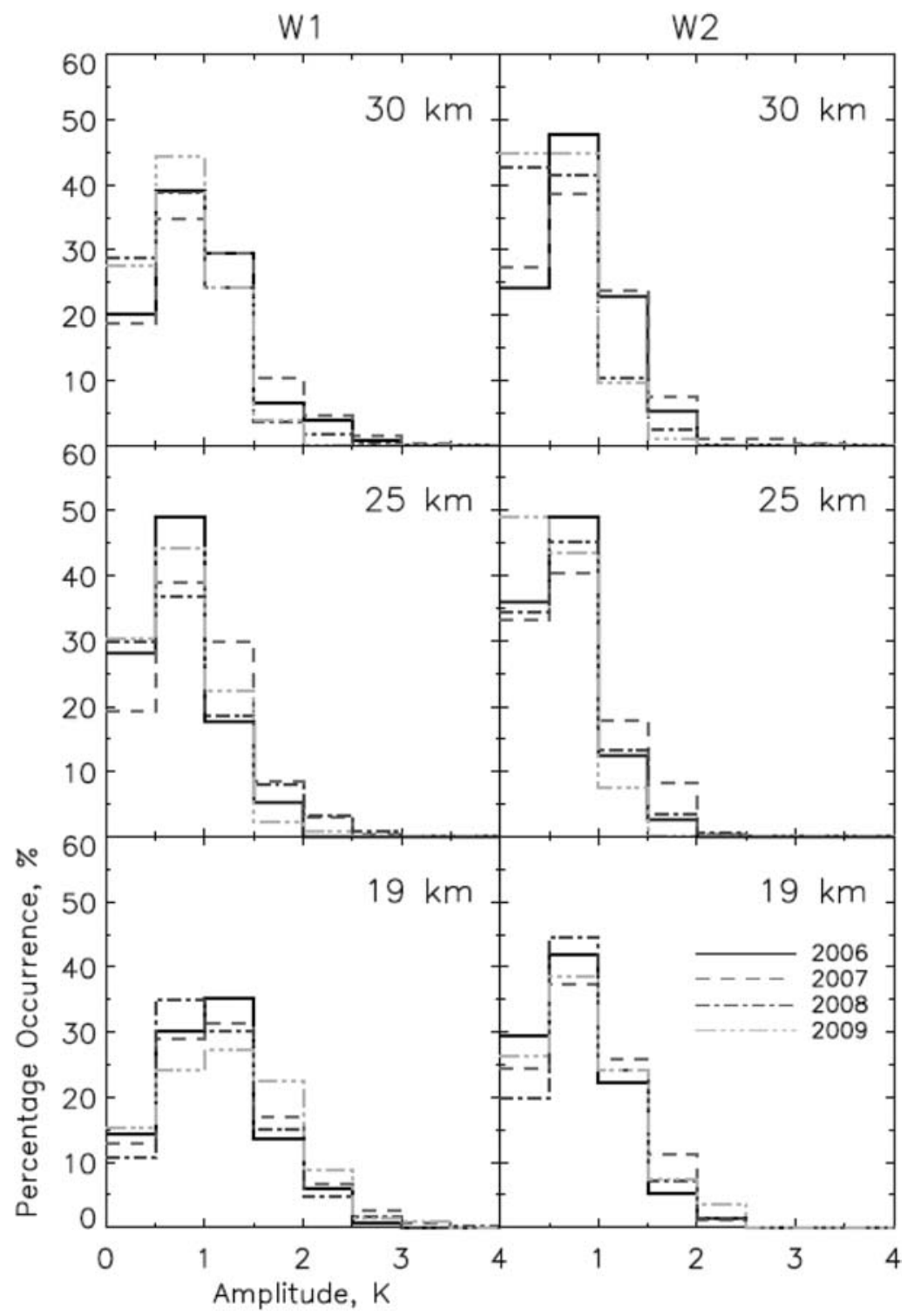

Fig. 5. Amplitude distributions of W1 (left column) and W2 (right column) at the three altitudes $19 \mathrm{~km}$ (bottom row), $25 \mathrm{~km}$ (middle row) and $30 \mathrm{~km}$ (top row).

damped at lower levels $(26-30 \mathrm{~km})$ and this slowly results in the descending motion of the westerlies, as is evident from the figure. It is interesting to discuss Fig. 3 once again at this point in the light of this understanding. It can be seen from Fig. 6 that during the period of February 2008 shown in Fig. 3 the zonal winds were easterlies up to $\sim 24 \mathrm{~km}$ and westerlies above this altitude. The easterlies favor the propagation of the eastward Kelvin waves and at a critical level (24-25 km here), the wave is damped and deposits its momentum. Hence, the amplitudes below this altitude are high and low above. This explains the beautiful eastward propagating structures at 19 and $25 \mathrm{~km}$ in Fig. 3 and the distorted and quasi-stationary structures at $30 \mathrm{~km}$. This, therefore, clearly shows that the energy of the Kelvin waves is used to feed the QBO, specifically the westerlies and hence these waves have an important contribution to the dynamics of UTLS. Similar interactions of the Kelvin waves with the QBO were observed by earlier authors. Shiotani and Horinouchi (1993) showed using 15 years of 

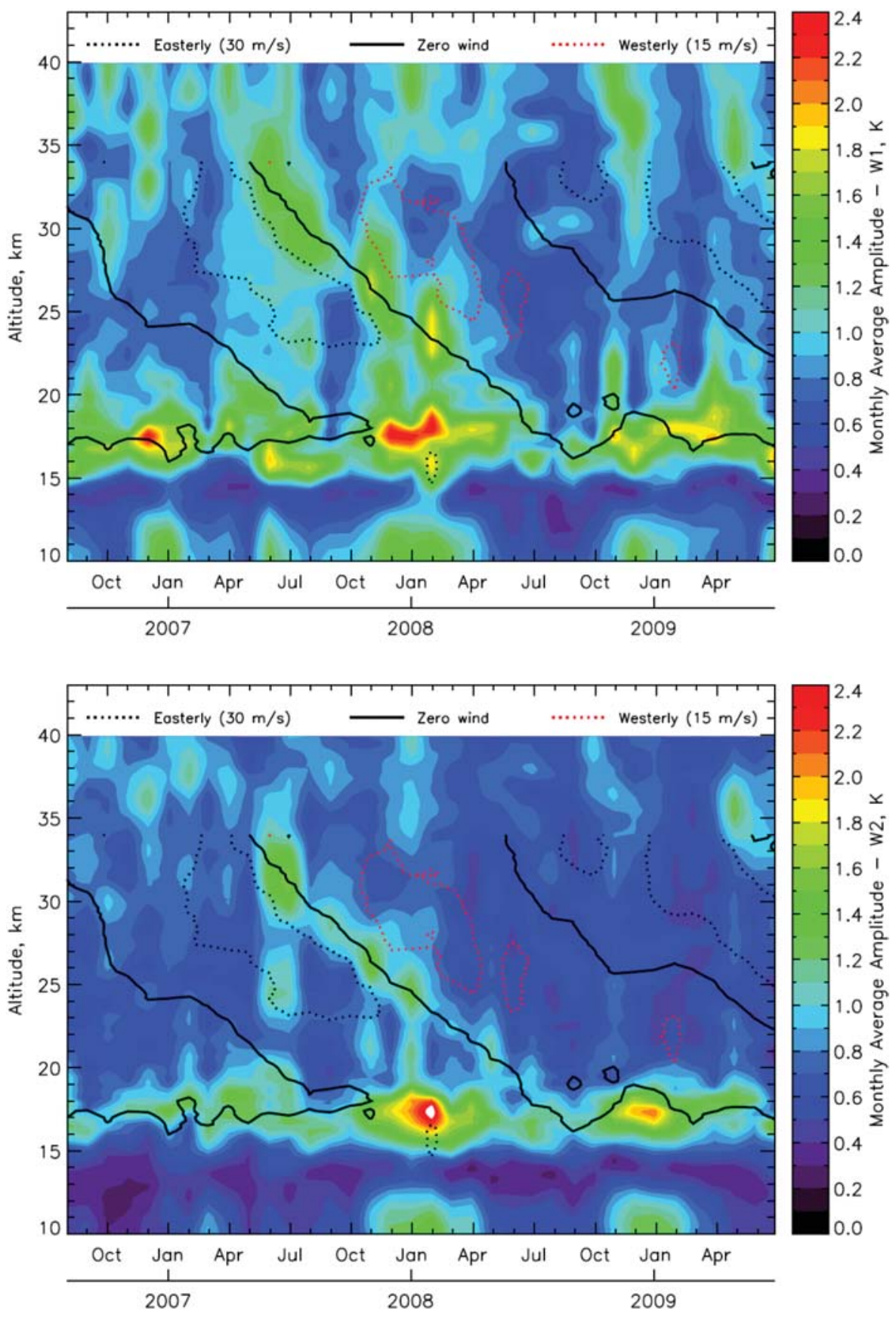

Fig. 6. Monthly mean amplitudes of W1 and W2 during the study period. Contours of zero-wind, strong easterlies $\left(30 \mathrm{~m} \mathrm{~s}^{-1}\right)$ and strong westerlies $\left(15 \mathrm{~m} \mathrm{~s}^{-1}\right)$ from the monthly mean zonal wind over Singapore are also plotted.

rawinsonde data at Singapore that the Kelvin wave activity was vigorous when the wind regime of the QBO rapidly changed from easterlies to westerlies. From the studies using observations of CLAES onboard UARS, Shiotani et al. (1997) showed that the slow Kelvin wave activity was vigorous during the easterlies and decreased during the westerlies. Randel and $\mathrm{Wu}$ (2005) also observed that the total large scale variance corresponding to both the Kelvin waves was high during the easterlies and drops 
down to very small values beyond the zero-wind line. The long term study by Ratnam et al. (2006) also showed similar results by considering the average amplitude of W1 and W2. In contrast to the earlier studies where the average amplitude was investigated, $\mathrm{W} 1$ and $\mathrm{W} 2$ are shown separately in the present study. It was seen and discussed in Fig. 4 that the amplitude of $\mathrm{W} 1$ is greater than that of W2 during $60 \%$ of the time. However, Fig. 6 shows that the monthly mean amplitude of W1 is always higher than that of W2 in the stratosphere and both are comparable only at the zero-wind levels.

Another important feature to be noted in this figure is that the amplitudes are always high near the tropopause region in comparison to the stratosphere. W1 shows high amplitudes in a wide region from 16 to $20 \mathrm{~km}$, while W2 shows the same in a narrower region from 16 to $18 \mathrm{~km}$ only. In addition, a strong annual variation of these Kelvin waves in the lower altitudes $(17-18 \mathrm{~km})$ with high amplitudes during November to February, the northern hemisphere winter. This shows that the Kelvin wave amplitudes do not depend on the background wind conditions near the tropopause. To understand this, we investigated the outgoing long wave radiation (OLR) and Fig. 7 shows the monthly mean OLR from 2006 to 2009 in the $\pm 10^{\circ}$ latitude region, obtained from the daily gridded OLR data available with the NOAA Earth System Research Laboratory, Physical Sciences Division. The daily data are available on a $2.5 \times 2.5$ latitude-longitude grid, with data gaps filled by linear interpolation to provide complete sampling. The figure shows that the OLR is quite low $\left(<210 \mathrm{~W} \mathrm{~m}^{-2}\right.$, blue region) during the northern hemisphere winter months in the $60-180^{\circ}$ longitude region, which is an indication of deep convection in the lower atmosphere. It is known that deep convection is an important source of small and large scale waves in the lower atmosphere (e.g., Salby and Garcia 1987). In the present study also, the low OLR in the winter months, coincides with the high amplitudes of Kelvin waves near the tropopause indicating the source of the later to be deep convection. This is consistent with the results of earlier authors (Randel and Wu 2005; Ratnam et al. 2006; etc.). Once produced, their upward propagation and the consequent transport of energy and momentum from the lower atmosphere to the higher altitudes depend on the stratospheric zonal winds, specifically the quasi-biennial oscillation.

The periods and the phase velocities of the

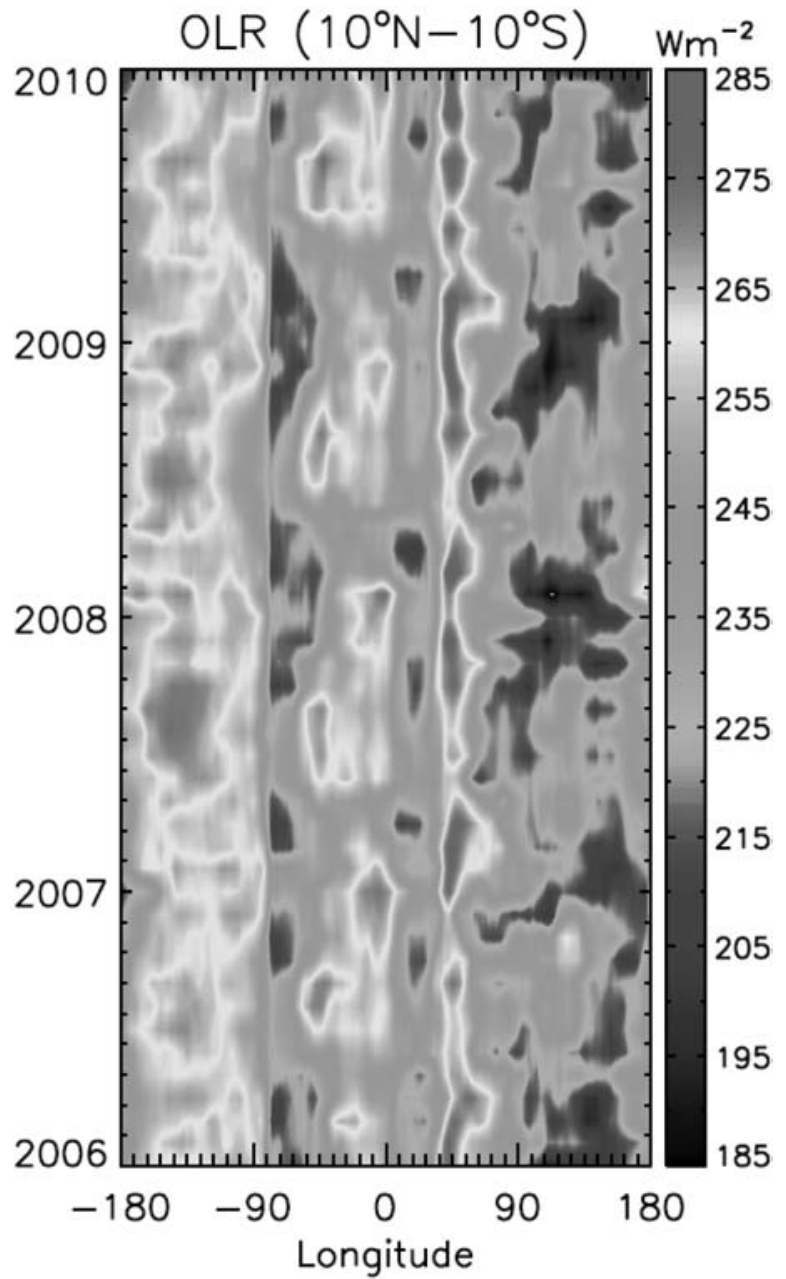

Fig. 7. Monthly mean outgoing long wave radiation (OLR) from 2006 to 2009 in the equatorial belt of $\pm 10^{\circ}$. Observe the low OLR in the $60-180^{\circ} \mathrm{E}$ longitude regions during the northern hemisphere winter months.

Kelvin waves are deduced to understand their propagation characteristics at different altitudes. Figure 8 shows the periods of the Kelvin waves W1 and W2 for the years from 2006 to 2009 at 19, 25 and $30 \mathrm{~km}$. The vertical bars denote the \pm one sigma variation. The period of each individual Kelvin wave event at an altitude was identified manually as the number of days taken by the wave maximum to travel $360^{\circ}$ and $180^{\circ}$ longitude for $\mathrm{W} 1$ and $\mathrm{W} 2$, respectively. The $\mathrm{W} 1$ and $\mathrm{W} 2$ waves were investigated separately by plotting the Hovmoller diagrams for the two waves using the fitted parameters, i.e., the amplitudes and phases from the 


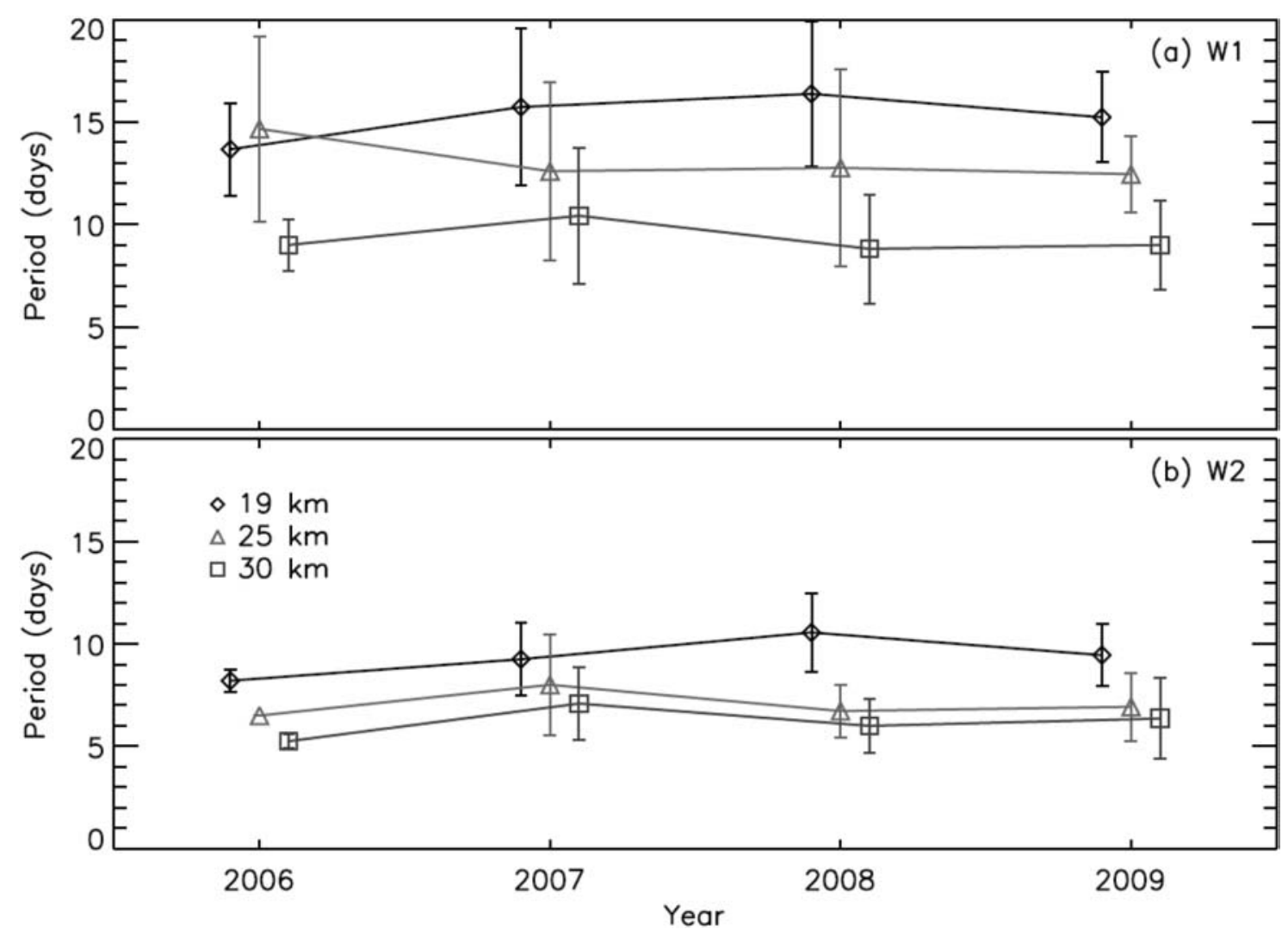

Fig. 8. The Kelvin wave periods deduced from the Formosat-3/COSMIC observations at different altitudes for the two waves W1 and W2.

"fitted T's". The average periods of W1 for all years are $15 \pm 3,13 \pm 4$, and $10 \pm 3$ days at altitudes 19,25 , and $30 \mathrm{~km}$, respectively and the average periods of W2 for all years are $10 \pm 2$, $7 \pm 2$, and $6 \pm 2$ days, respectively. It should be noted here that these standard deviations are geophysical and are due to the variation in the periods of the individual Kelvin wave events and that the identification of the period for a single Kelvin wave event is \pm one day. These periods show that both waves are slower at lower altitudes and faster at higher altitudes. From the figure it can also be seen that there is no significant year to year variation in the periods of the Kelvin waves of both wave numbers within one sigma. The phase velocities of the Kelvin waves are shown in Fig. 9 and it can be seen that the velocities at higher altitudes are high in comparison to that at lower altitudes. For $\mathrm{W} 1$, the average phase velocities are $31 \pm 7$, $40 \pm 13$, and $53 \pm 14 \mathrm{~m} / \mathrm{s}$ and for W2 are $25 \pm 5$, $34 \pm 8$ and $37 \pm 11 \mathrm{~m} / \mathrm{s}$, at the three altitudes, respectively. It should be noted that the phase veloc- ity of $\mathrm{W} 1$ is greater than that of $\mathrm{W} 2$ at any given altitude.

The periods and the phase velocities have been deduced, in the present study, with more accuracy owing to the high spatial and temporal resolution of the F-3/C temperature data. The periods of the waves of both wave numbers were found to be in the range 10-20 days and mostly in between 10-15 days at $20 \mathrm{~km}$ in the long term study for the period 2001-2005 (Ratnam et al. 2006). Tsai et al. (2004) reported the periods of the waves at $19 \mathrm{~km}$ altitude to be 12.4-14 days for $\mathrm{W} 1$ and 9.3-11 days for W2 during the period 2001-2002. During the CPEA campaign from April to May 2004, Kelvin waves with periods of 10-12 days were observed at $17 \mathrm{~km}$ (Tsuda et al. 2006) and a 7-day wave was observed at 20-21 km (Sridharan et al. 2006). The periods deduced in the present study at $19 \mathrm{~km}$ are in very good agreement with these earlier studies. In addition, due to the availability of the long dataset, it had been possible to obtain the average periods and phase velocities during each year for 


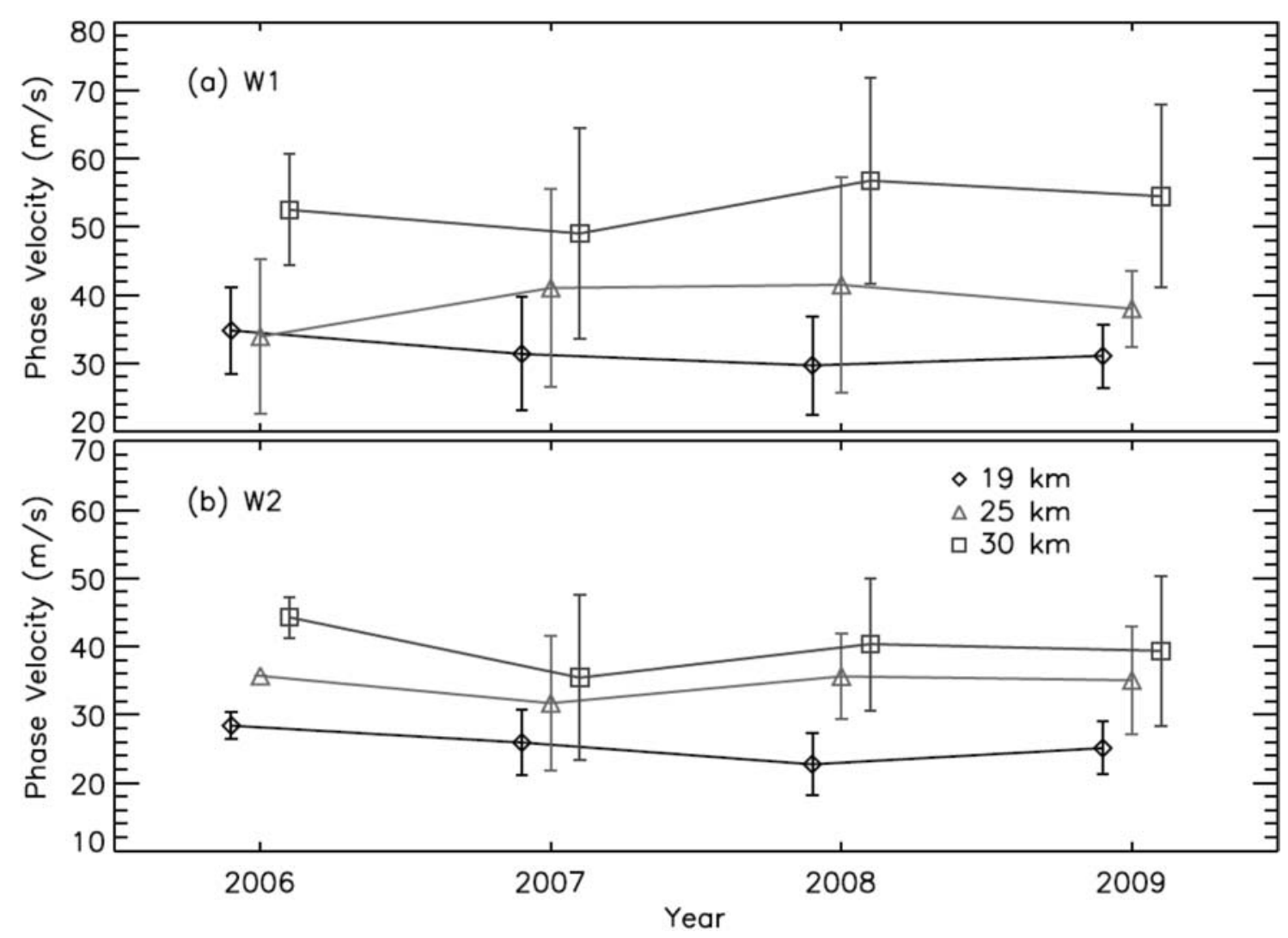

Fig. 9. The Kelvin wave phase velocities deduced from the Formosat-3/COSMIC observations at different altitudes for the two waves W1 and W2.

both the waves at different altitudes in the UTLS region. The average Kelvin wave periods and the phase velocities are similar during the years from 2006 to 2009, though the amplitudes and propagation characteristics depend on the stratospheric winds. Wallace and Kousky (1968) showed the presence of the slow waves of periods 10-20 days in the lower stratosphere using radiosonde measurements and Hirota (1978) showed the presence of the fast waves in the upper stratosphere using the rocketsonde measurements. Figures 8, 9 clearly show the existence of both the slow Kelvin waves in the low altitudes and the fast Kelvin waves at higher altitudes from the same dataset and on a global scale. This is the most important result of the present study. Also, the earlier studies were aimed at characterizing the Kelvin waves during short time periods of one year and less (Wallace and Kousky 1968; Tsuda et al. 2006; etc.). The study by Ratnam et al. (2006) is the only long term study so far to investigate the Kelvin waves which used the CHAMP data during 2001-2005. The present study, in continuation and in addition to this work, has investigated the Kelvin waves of zonal wave numbers 1 and 2 during the period 2006-2009 and the properties of these waves at different altitudes have been deduced with better accuracy with the F-3/C data.

\section{Summary}

A detailed study of the equatorial Kelvin waves using the temperature data from the GPS RO soundings of $\mathrm{F}-3 / \mathrm{C}$ has been presented in this paper. The dominant waves with wave numbers 1 and 2 have been investigated and it has been found that both waves exist simultaneously and the amplitude of $\mathrm{W} 1$ is greater during $60 \%$ of the time. The monthly mean amplitudes, however, show that W1 dominates at all times. A statistical study also has been conducted which shows that the amplitudes of $\mathrm{W} 1$ are larger at $19 \mathrm{~km}$ and the distribution is broader and at higher altitudes the amplitudes are smaller and the distributions are narrower. This study has shown that the amplitudes of both the 
Kelvin waves in the stratosphere were high during the easterly phase of the QBO and maximum when the easterlies change to westerlies, consistent with earlier studies. Near the tropopause region, an annual variation is observed in the wave amplitudes with maxima during the northern hemisphere winter months in consonance with the seasonal variation in deep convection. The periods and the phase velocities of the waves with wave numbers 1 and 2 have been deduced and clear evidence is shown for the presence of slow waves at low altitudes and fast waves at higher altitudes using the same dataset. The average Kelvin wave periods and the phase velocities are similar during the years from 2006 to 2009 , though the amplitudes and propagation characteristics, especially, at the higher altitudes depend on the stratospheric winds.

\section{Acknowledgements}

The authors thank the United Kingdom Meteorological Office for providing free access to the radiosonde data. Interpolated OLR data provided by the NOAA/OAR/ESRL PSD, Boulder, Colorado, USA, from their Web site at http://www.esrl.noaa .gov/psd/. CJP and UD are supported by the NSC of Taiwan through grant NSC 99-2111-M-008-006MY2.

\section{References}

Baldwin, M. P., et al., 2001: The quasi-biennial oscillation, Rev. Geophys., 39, 179-229, doi:10.1029/ 1999RG000073.

Canziani, P. O., J. R. Holton, E. Fishbein, L. Froidevaux, and J. W. Waters, 1994: Equatorial Kelvin waves: A UARS-MLS view, J. Atmos. Sci., 51, 3053-3076.

Chang, L. C., S. E. Palo, H. L. Liu, T. W. Fang, and C. S. Lin, 2010: Response of the thermosphere and ionosphere to an ultra fast Kelvin wave, J. Geophys. Res., 115, A00G04, doi:10.1029/ 2010JA015453.

Fong, C. J., N. L. Yen, C. H. Chu, S. K. Yang, W. T. Shiau, C. Y. Huang, S. Chi, S. S. Chen, Y. A. Liou, and Y. H. Kuo, 2009: FORMOSAT-3/ COSMIC spacecraft constellation system, mission results, and prospect for follow-on mission, Terr. Atmos. Oceanic Sci., 20, 1-19, doi: 10.3319/ TAO.2008.01.03.01(F3C).

Fueglistaler, S., A. E. Dessler, T. J. Dunkerton, I. Folkins, Q. Fu, and P. W. Mote, 2009: Tropical tropopause layer, Rev. Geophys., 47, RG1004, doi:10.1029/2008RG000267.

Hayashi, H., J. I. Furumoto, Xinan Lin, Toshitaka Tsuda, Yoshinori Shoji, Yuichi Aoyama, and Ya- suhiro Murayama, 2009: Validation of refractivity profiles retrieved from FORMOSAT-3/COSMIC radio occultation soundings: Preliminary results of statistical comparisons utilizing balloon-borne observations, Terr. Atmos. Oceanic Sci., 20, 51-58, doi: 10.3319/TAO.2008.01.21.01(F3C).

Hirota, I., 1978: Equatorial waves in the upper stratosphere and mesosphere in relation to the semiannual oscillation on the zonal wind, J. Atmos. Sci., 35, 714-722.

Holton, J. R., and R. S. Lindzen, 1968: A note on Kelvin waves in the atmosphere, Mon. Wea. Rev., 96, 385-386.

Holton, J. R., and R. S. Lindzen, 1972: An updated theory for the quasi-biennial cycle of the tropical stratosphere. J. Atmos. Sci., 29, 1076-1080.

Kishore, P., S. P. Namboothiri, J. H. Jiang, V. Sivakumar, and K. Igarashi, 2009: Global temperature estimates in the troposphere and stratosphere: A validation study of COSMIC/FORMOSAT-3 measurements, Atmos. Chem. Phys., 9, 897-908, doi:10.5194/acp-9-897-2009.

Matsuno, T., 1966: Quasi-geostrophic motions in the equatorial area, J. Meteor. Soc. Japan, 44, 25-43.

Mote, P. W., T. J. Dunkerton, and D. Wu, 2002: Kelvin waves in stratospheric temperature observed by the Microwave Limb Sounder, J. Geophys. Res., 107, doi:10.1029/2001JD001056.

Randel, W. J., and F. Wu, 2005: Kelvin wave variability near the equatorial tropopause observed in GPS radiosonde occultation measurements, J. Geophys. Res., 110, D03102.

Randel, W. J., F. Wu, and W. R. Rios, 2003: Thermal variability of the tropical tropopause region derived from GPS/MET observations, J. Geophys. Res., 108(D1), 4024, doi:10.1029/2002JD002595.

Rao, D. N., M. V. Ratnam, Sanjay Mehta, Debashis Nath, S. Ghouse Basha, V. V. M. Jagannadha Rao, B. V. Krishna Murthy, T. Tsuda, and Kenji Nakamura, 2009: Validation of the COSMIC radio occultation data over Gadanki $\left(13.48^{\circ} \mathrm{N}, 79.2^{\circ} \mathrm{E}\right)$ : A tropical region, Terr. Atmos. Oceanic Sci., 20, 59-70, doi: 10.3319/TAO.2008.01.23.01(F3C).

Ratnam, M. V., T. Tsuda, T. Kozu, and S. Mori, 2006: Long-term behavior of the Kelvin waves revealed by CHAMP/GPS RO measurements and their effects on the tropopause structure, Ann. Geophys, 24, 1355-1366.

Salby, M. L., and R. R. Garcia, 1987: Transient response to localized episodic heating in the tropics, I, Excitation and short-time near-field behaviour. $J$. Atmos. Sci., 44, 458-498.

Salby, M. L., D. L. Hartmann, P. L. Bailey, and J. C. Gille, 1984: Evidence for equatorial Kelvin modes in Nimbus-7 LIMS, J. Atmos. Sci., 41, 220-235.

Shiotani, M., J. C. Gille, and A. E. Roche, 1997: Kelvin waves in the equatorial lower stratosphere as re- 
vealed by cryogenic limb array etalon spectrometer temperature data, J. Geophys. Res., 102, 2613126140.

Shiotani, M., and T. Horinouchi, 1993: Kelvin wave activity and the quasi-biennial oscillation in the equatorial lower stratosphere, J. Meteor. Soc. Japan, 71, 175-182.

Sridharan, S., T. Tsuda, T. Nakamura, T. Kozu, S. Mori, and J. M. Russell, 2006: Observations of the 7-day Kelvin wave in the tropical atmosphere during the CPEA Campaign, J. Meteor. Soc. Japan, 84A, 259-275.

Tsai, H.-F., T. Tsuda, G. A. Hajj, J. Wickert, and Y. Aoyama, 2004: Equatorial Kelvin waves observed with GPS occultation measurements (CHAMP and SAC-C), J. Meteor. Soc. Japan, 82B, $397-$ 406.

Tsuda, T., M. Nishida, C. Rocken, and R. H. Ware, 2000: A global morphology of gravity wave activity in the stratosphere revealed by the GPS occultation data (GPS/MET), J. Geophys. Res., 105 (D6), $7257-7273$

Tsuda, T., M. V. Ratnam, T. Kozu, and S. Mori, 2006: Characteristics of 10-day Kelvin wave observed with radiosondes and CHAMP/GPS occultation during the CPEA campaign (April-May, 2004), J. Meteor. Soc. Japan, 84A, 277-293.

Wallace, J. M., and V. E. Kousky, 1968: Observational evidence of Kelvin waves in the tropical stratosphere, J. Atmos. Sci., 25, 900-907. 